\title{
Architectural development of recreation facilities in Ukraine and internationally
}

\begin{abstract}
The paper presents the definition of key terms distinguished and used in the field of vacationing, leisure, and recreation. It explains their similarities and differences. The classification has been developed for holiday centers according to their intended use, forms of activity, and types of services. Key criteria for their classification are provided. It analyzes the experience of designing contemporary recreation centers in Ukraine and all over the world, and identifies key trends in the development of their architecture and infrastructure in general.
\end{abstract}

Key words: holiday, recreation, tourism, leisure, recreation facilities, holiday centers, architecture

\section{Problem statement}

Today, a person of the $21^{\text {st }}$ century, usually thirsty for new knowledge and exploration, requires to have opportunities for relaxation above all things. Humankind is trapped within information noise and the non-stop "busyness". As a result, people are most prone to loneliness and passive pastime. On the other hand, it leads to stress and mental disorders.

Furthermore, the global pandemic had a major effect on tourism in any country. People lost opportunities to travel the world, and started actively using the services of their national holiday centers or camps. Closed external border pushed Ukrainians to travel more within Ukraine. Therefore, there is a need to create new holiday centers and renovate the old ones, such as recreation places, facilities, and resort areas where people could have useful and fun time.

\section{Analysis of recent research and publications}

Publications available in Ukraine that explore into the topic of recreation facilities include the noteworthy research works by representatives of the Lviv Architectural School - I. Rusanova and H. Shulha. An important contribution to the research of recreation resources of Ukraine and resort studies was made by N. Fomenko. Scholars M. Pokolodna and I. Polchaninova produced a detailed study of recreation facilities in the world, Ukraine's tourist resources among them.

\section{Objective of the article}

The essay's objective is to highlight the challenges in functioning of recreation facilities in Ukraine and internationally, to list the possibilities to update their architecture and expand the range of services by analyzing international experience and describing current trends in the development of architecture of recreational facilities in global practices.

\section{Results and discussions}

Relaxation plays an important role in people's life, as it helps reduce the tension and fatigue after a hard work period. A typical feature for any rest period is staying in the open air and doing certain activities untypical for people in usual contexts. This peculiarity is reflected by the term "recreation" - it is a system of measures related to the use of people's free time for their recreational and sporting activities, for cultural acquaintance on dedicated sites located outside their living places (Shmyh, R., Boiarchuk, V., Dobrianskyj, l. and Barabash, V., 2010).

There are three forms of recreation: vacationing, tourism, treatment (wellness).

Rest is a set of special activities of social, educational, medical, hygienic, and sporting nature that provide for organization of leisure, restoration of physical and mental functions of the body, and contribute to spiritual growth and community commitment of people (Verkhovna Rada of Ukraine, 2020. Law of Ukraine from 01.01.2020 № 375-VI: On Rest and Recreation of Children). To provide for such activities, recreation facilities are designed. It is a set of recreational facilities with over 1000 seats sharing the same functional program: rest relaxation (World of geography and tourism, 2020). Tourism is a temporary leave of a person from the permanent residence place for wellness, professional and business or other purposes without conducting paid activities in the place of stay. Usually, these are walking trips or trips by various vehicles (Verkhovna Rada of Ukraine, 2020. Law of Ukraine from 16.10.2020 № 324/95-BP: On Tourism).

The terms of "tourism" and "recreation" are similar in their meaning as many sources treat them as synonyms. However, the concept of «recreation» is

* Viktor Proskuryakov, Prof. D. Sc., Ph.D. arch., Lviv Polytechnic National University, Ukraina, https://orcid.org/0000-0003-1022-8984 , e-mail: Viktor.I.Proskuriakov@lpnu.ua

I** vanna Voronkova, Ph.D., As. Prof., Lviv Polytechnic National University, https://orcid.org/0000-0003-2711-166X, e-mail: ivanna. 
much broader because it includes all types of individual's activities in their free time from work spent outside their homes. The concept of "tourism" is more narrow because it is the process of consuming certain services by an individual, such as buying certain products, goods, and also using the resource capacity of the area. Health resort treatment (wellness) - is medical aid administered for preventive, therapeutic, or rehabilitation purposes with the use of natural medicinal factors in the settings of a resort or a health recovery area / sanatorium resorts. Sanatorium and resort field in Ukraine has traditionally been an integral part of the national health care system, enabling efficient prevention of disease (Ministry of Social Policy of Ukraine, 2020)

Rest and leisure options are provided by various kinds of entities: sports and leisure centers (clubs, swimming pools, skating-rinks), entertaining places (casino, zoos, parks), spectacular facilities (theaters, cinemas, television), and cultural educational places (libraries, museums, exhibitions). They are provided by recreation facilities and should agree with the architectural and planning solutions in the designed buildings.

Recreation facilities are classified according to the following criteria: orographic (lowland, highland, hilly, mountainous), sectoral geographic (seaside, continental, subcontinental, oceanic), climate zoned recreation (highland climate, moderate climate with seasonal effect, Mediterranean, tropical), landscape-based (seaside, continental, sandy, shingle, rocky block, lakeside, forested areas, alpine meadows), specific natural (medicinal waters, thermal, subequatorial saline, muddy, naphthalan, phytoncide, aroma therapy), social and economic (local significance, domestic, international class, low-cost, high-cost, upmarket, narrow profile, wide profile).

Recreation facilities and resorts are differentiated by their intended use: therapy and wellness, ski resorts, seaside. Each group has a typical set of services that depend on their location, intended use, and class of the recreation facility. For example, ski resorts offer skiing, snowboarding, sleighing, carting, skating, bicycles, horse riding, swimming in the pools, spa centers, wellness programs (if the area is equipped with certain medicinal resources, such as mineral waters). Architectural and planning solutions of such resorts imply having restaurants, cafés, clubs, art spaces, reading places, sporting grounds, and workout and fitness facilities, viewing decks, swimming pools, saunas, open-air terraces, etc.

International architectural practice shows certain algorithms in design of ski facilities: first, an initial concept for the resort is identified, a market analysis is conducted for prospective customers, an optimal land plot is searched and selected, land plot survey (relief configuration, climate conditions, recreation capacity, history), financial relevance, general principles of the project are identified, throughput capacity of pistes and the footing area are estimated, such as a scheme is developed for the location of trails and design of the footing area (Rutynskyy, M., 2007).

An interesting trend in the design of recreation facilities is the use of viewing decks such as bridges or trails. This is the way for modern architects to boldly combine detached buildings and create scenic viewpoints for visitors, and develop interesting landscaping.

A bright illustration could be an International Resort in Beijing intended to renovate the resort homestead (II. 1). The SYN Architects company designed a fresh and logical concept. Architects managed to transform the locality surrounded by water and mountains into a "natural desert» by creating a panoramic view. They succeeded to do it by combining open rectangular terraces of different sizes and structures with mountain-

II. 1. International resort in Beijing, source: https://www.archdaily.com/883534/beijing-jinhai-lake-international-resort-syn-architects?ad_ source=search\&ad_medium=search_result_all [Date of reference 29 February 2021]
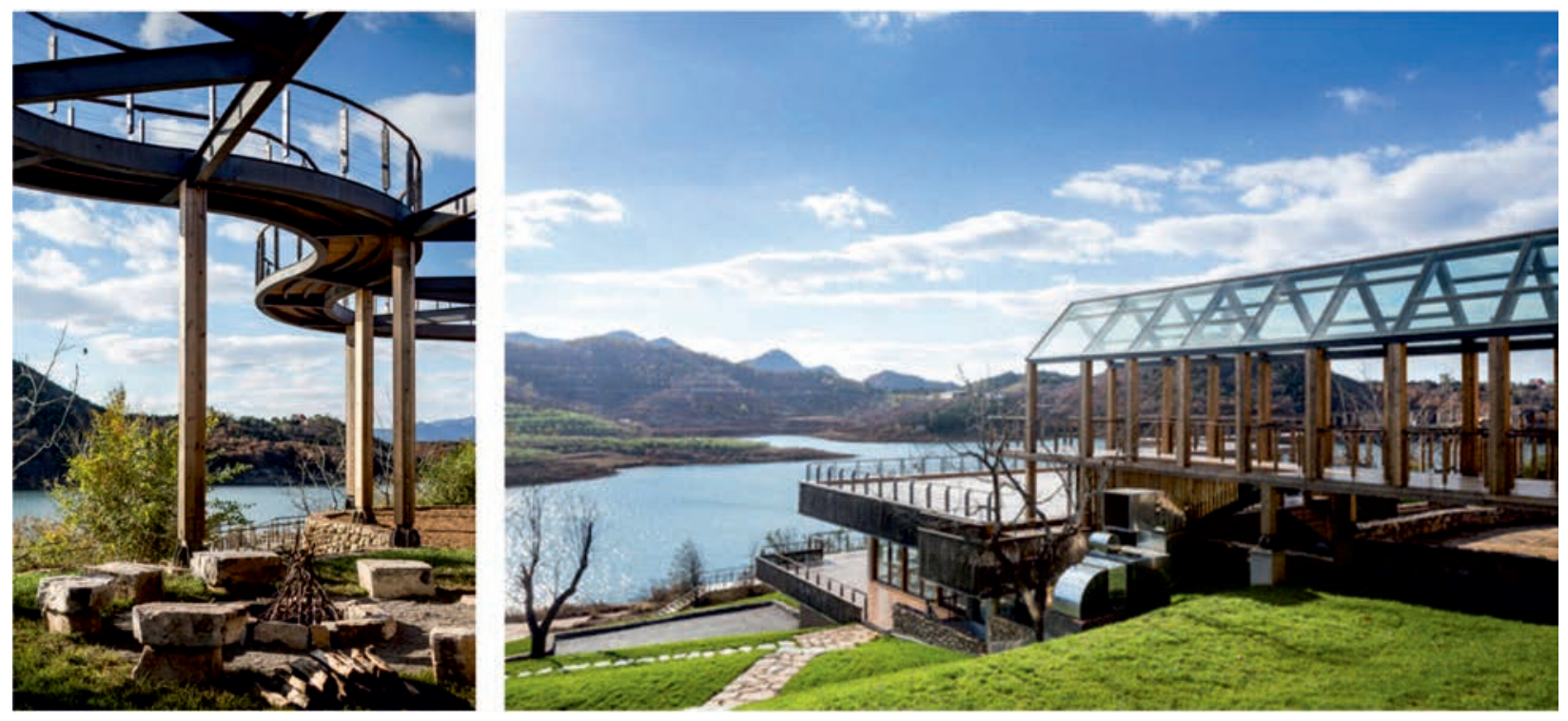

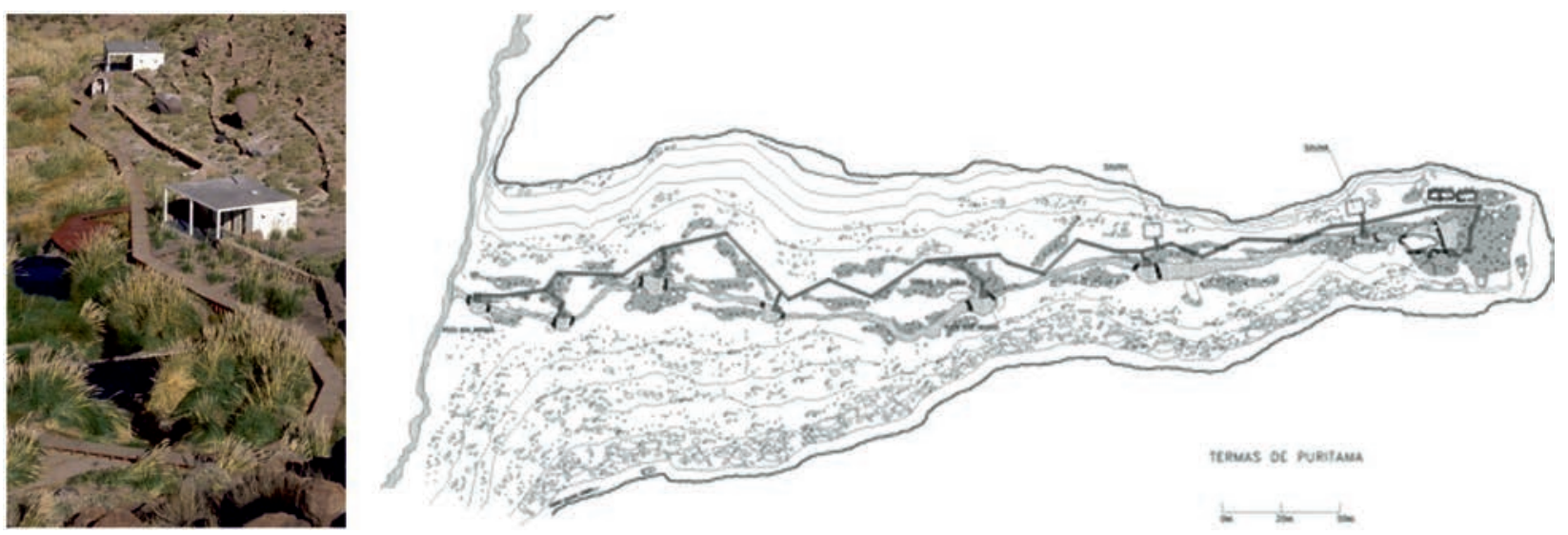

II. 2. Hot springs resort in Chile source: https://www.archdaily.com/5955/puritama-hot-springs-german-del-sol?ad_source=search\&ad_ medium $=$ search_result_projects [Date of reference 29 February 2021]

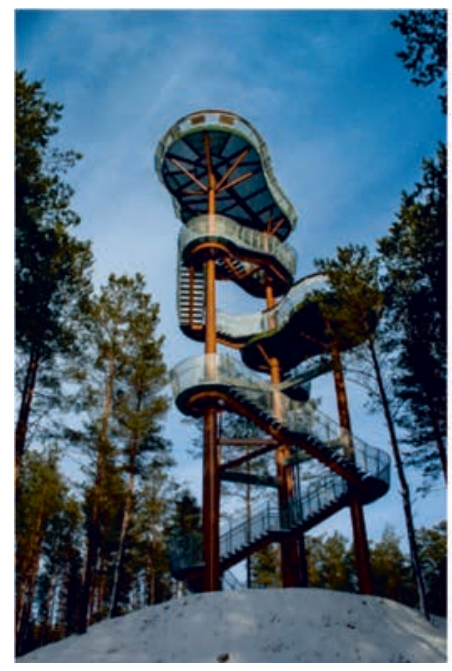

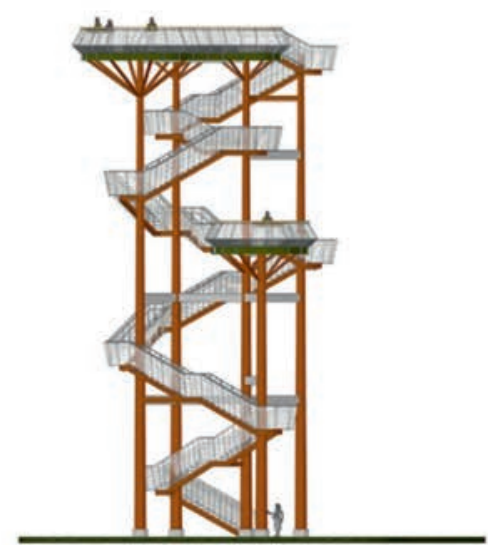

SOUTH ELEVATION

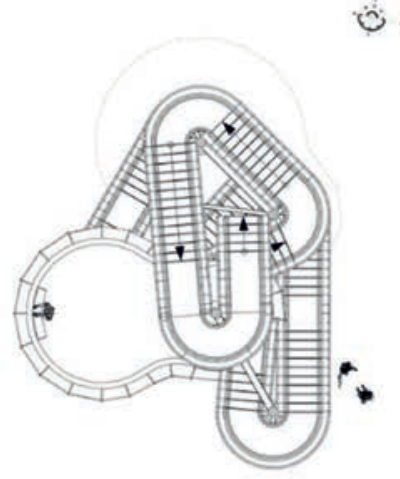

PUNAT +2000

II. 3. Watchtower in Lithuania source: https://www.archdaily.com/775818/observation-tower-arvydas-gudelis?ad_source=search\&ad medium =search_result_all [Date of reference 29 February 2021]

ous patterns. A key detail of the facility is a panoramic restaurant and a glass deck that harmoniously merged architecture with nature. The buildings scattered according to the architectural and planning solutions were connected by architects with the help of designed paths that fit various altitudes and provide access to all buildings. The paths also serve as viewing decks. To smooth the spatial voluminous composition, they used the rounded forms of paths imitating the clouds. The design used such materials as firewood, pebble stone, and wood abundant in the area (ArchDaily, 2020. Beijing Jinhai Lake International Resort).

A different but no less interesting project is the implemented design for Puritama Hot Springs. It was developed near a thermal river in Chile (II. 2). Landscape design shows a link between the facility and the virgin nature of the location. With the help of above-ground paths, the architecture of the recreation facility is integrated within the environment. Structures scattered along the river are made of white concrete, which also reinforces the wild life of the designed territory (ArchDaily, 2020. Puritama Hot Springs).
Another peculiarity in designing recreation facilities is to create viewing decks as separate architectural facilities. An interesting example for such solution is the Watchtower in Lithuania (II. 3). The watchtower is located on the high bank of the Nemunas river. Therefrom, beautiful scenery opens onto the river, the islands, and the pine forests of the Jukia area. The watchtower is a detached architectural building but it does not dominate over the landscape at all. Conversely, it harmoniously fits the environment. A form, size, and color of the main columns of the watchtower and the distances kept between them make a small group of trees, the same as the forest around. You can reach the top of the watchtower by the staircase that is chaotically winding between the columns, the same as paths in a forest. Climbing the top of the watchtower one can gradually discover the new landscapes. However, the best view is available on the top platform. With metal perforations in the staircase, they managed to create the lightness of the structure itself and to combine it with nature (ArchDaily, 2020. Observation Tower). 

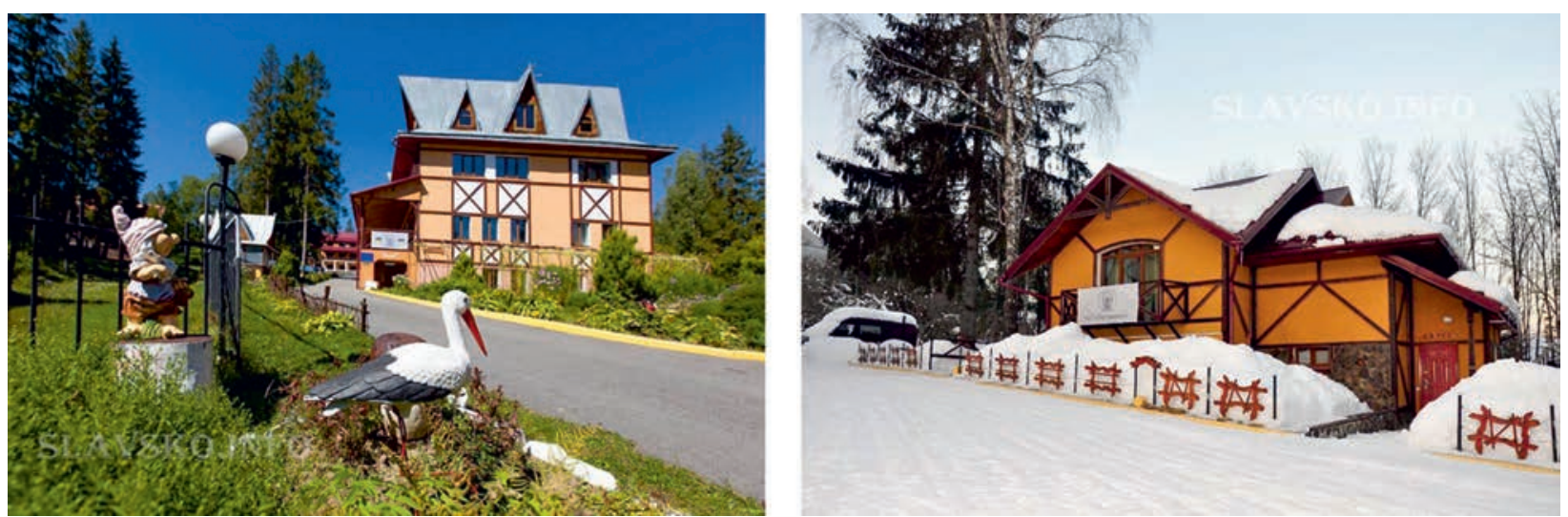

II. 4. "Politechnik-2" recreation facility in Slavske, source: http://www.karpaty-slav.com/politeh.html [Date of reference 7 March 2021]
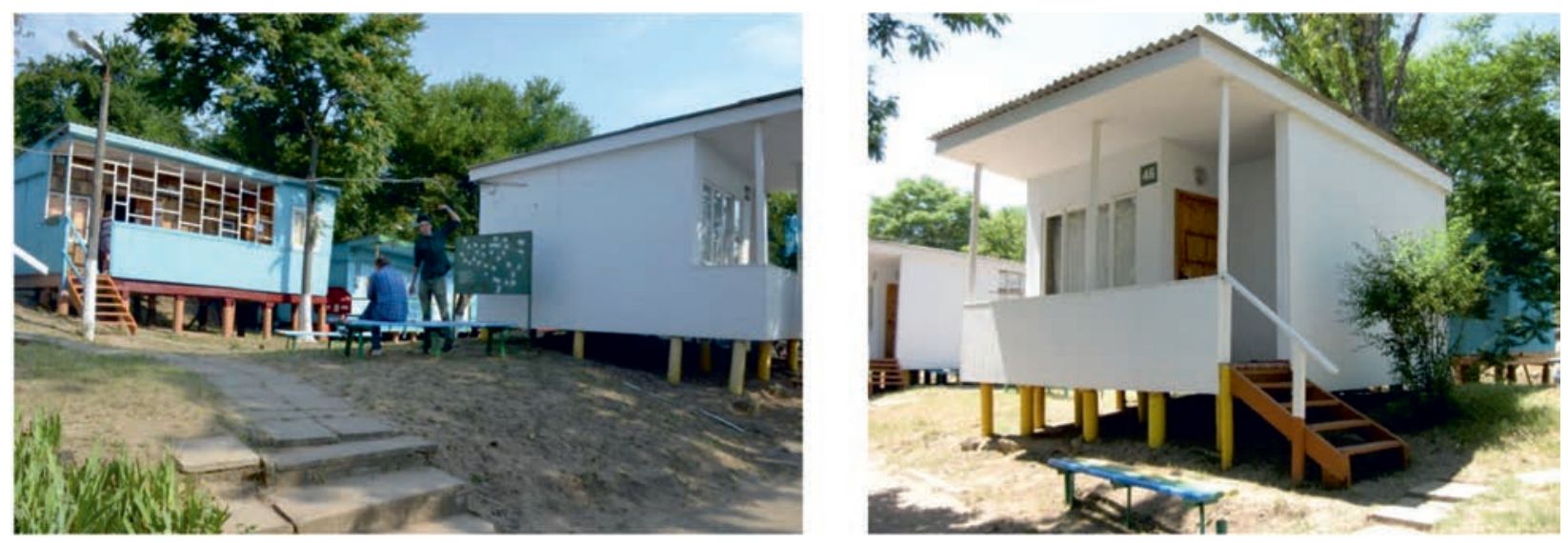

II. 5. "Akademichnyi" recreation facility in Chornomorsk, source: a) https://nubip.edu.ua/node/10227; b) https://nubip.edu.ua/node/62193 [Accessed 7 March 2021]

Unlike the foreign counterparts, most Ukrainian recreation facilities that are maintained from the central budget have a typical simple architecture and design. On the other hand, they offer a wide range of services. The "Politechnik-2» recreation facility in Slavske (II. 4) owned by the Lviv Polytechnics National University is located in a mountainous area. Therefore, it offers various kinds of outdoor activities in the mountains. In wintertime, it is skiing and snowboarding, with the available skiing pistes of different complexity. To function in other times of the year, the recreation facility has a stadium, a sporting ground for volleyball, basketball, mini football, table tennis and billiards facilities; one can visit a sauna, and take paid hiking tours along the mountain slopes. The recreation center includes 4 buildings, each of which has the basic list of room types: hotel rooms, sanitary and technical facilities, recreation areas. The canteen and the kitchen are located in the main building (II.4). Façades of buildings are made in eclectic style, with elements of

II. 6. Resort town of Bukovel, source: a) https://travel.24tv.ua/vidkriye-bukovel-zimoviy-sezon-vlasnik-kurortu-ostanni-novini_n1474449; b) https://ekotur.com.ua/packages/relaks-tur-bukovel/ [Accessed 7 March 2021]
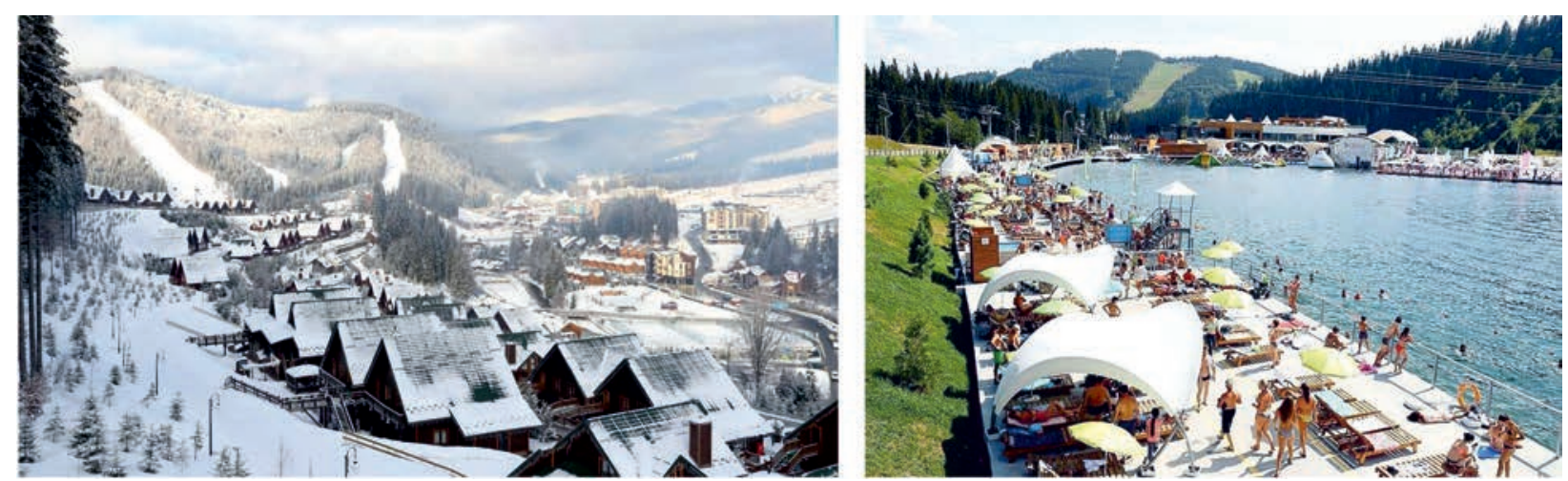


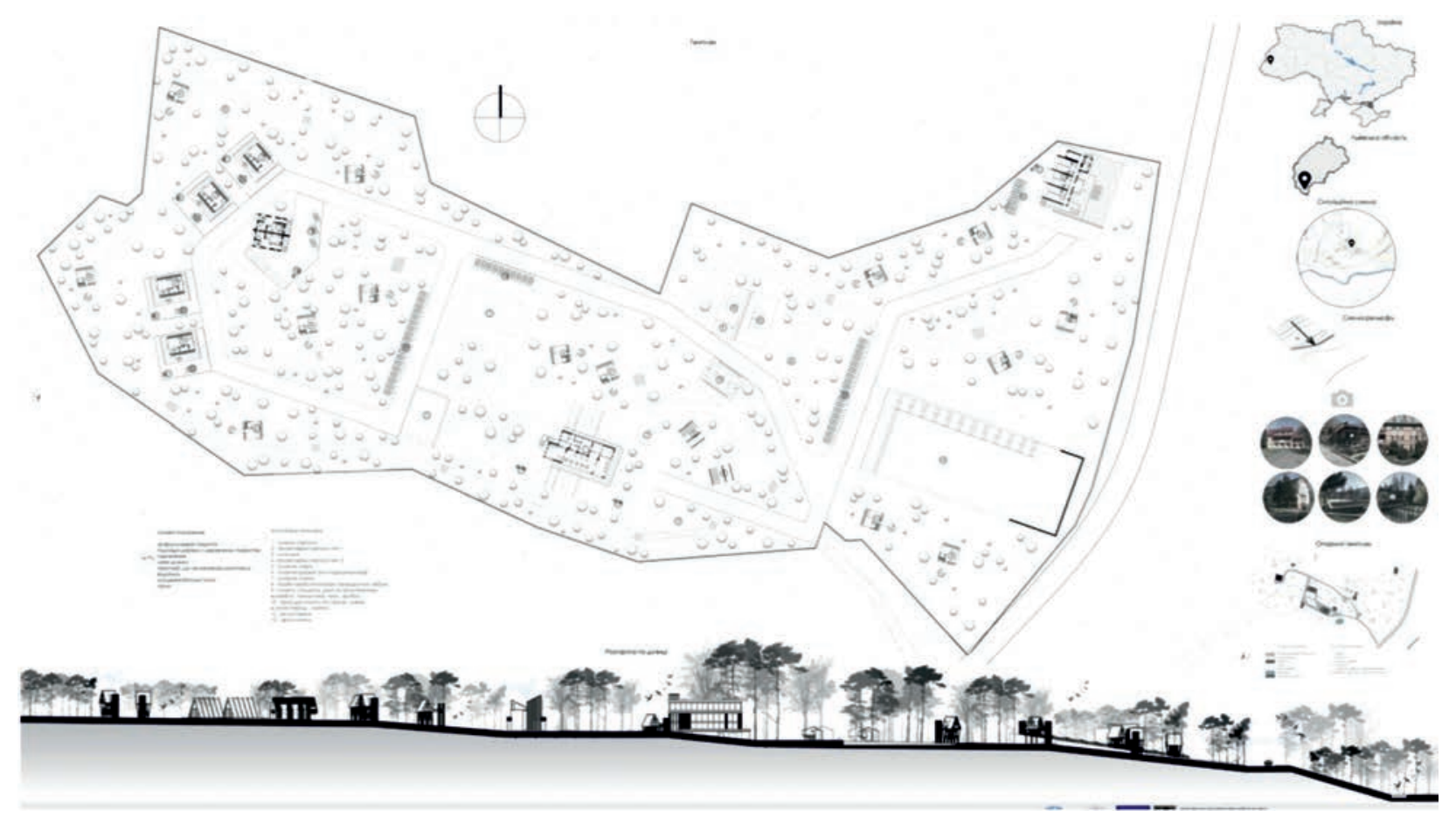

II. 7. Draft design for architectural development at the Politechnick-2 recreation camp, source/author.....

wooden architecture and Hutsul patterns. Moreover, it is noteworthy to highlight the brickwork of the semi-basement floor typical for architecture of the Carpathians. Compared to international counterparts, the architecture of the "Politechnik-2" recreation facility needs more energy efficient solutions and moderate color solutions of the façades (Karpaty-Slavsko, 2020).

"Akademichnyi" recreation facility in Chornomorsk managed by the National University of Ukraine of Bioresources and Natural Resources Use (II. 5) is located at the Black Sea coast. The range of services includes a paddleboats rental, water rides, motorboat excursions along the coast. The facility includes 26 detached houses fitted with beds, individual bathrooms with a walkin shower, a hot water boiler, and a fridge. However, it must be mentioned that the houses require renovation and upgrade, while the materials they are constructed of are not energy-efficient (NUBIP, 2020).

One of the best mountain skiing resorts in Ukraine is by all means the resort town of Bukovel (II. 6). It has been rapidly growing and hosting ab. $2 \mathrm{mln}$ tourists annually, from all over the world. Today, Bukovel is a major recreation, athletic, and sporting center. The development strategy was developed by Canadian engineers and environmentalists. The resort offers both winter activities (skiing, snowboarding, sleighing) and summertime leisure, too. In summer, they host competitions in triathlon and cycling. There are training facilities for Ukrainian boxing teams. Summer activities offered include 4-wheeler cross-country driving, horse riding, forest hiking, etc. (Procherk.info, 2021).

The relevance of tourism development incentivized the Lviv architectural school to conduct the academic re- search and design in this area. The research focus was on the upgrade of architecture and infrastructure expansion in recreation camps and facilities in Ukraine. One of the pioneering solutions was offered in the work by an associate professor Ivanna Voronkova and an architect Victoria Marchuk. They elaborated the draft design to enhance the architecture at the Politechnick-2 recreation camp in Slavske township (II. 7). According to the suggested design proposal, the acting recreation place will expand the range of services, both for winter time, and summer and autumn season. The recreation camp was largely upgraded: pedestrian walkways and motor roads were ramified, the buildings added (two types of modern cottages have been designed), private car and bicycle parking added, sleighing slope designed, and two open-air film theaters. The design concept was to arrange some new spaces for the "Politechnic-2" recreation camp but also to renovate the existing structures: the available buildings are suggested to be refurnished in a conventional Carpathian style.

\section{Conclusions}

Analysis of design practices for modern recreation facilities in Ukraine and resort areas in the world highlighted key trends for their development, such as taking into account their intended use and financial relevance, identifying the needs of potential users and the respective expansion of services on offer, full use of natural resources of their locations, and the improvement of architectural-spatial and functional-planning component of the holiday centers. 


\section{REFERENCES}

[1] Shmyh, R., Boiarchuk, V., Dobrianskyj, I. and Barabash, V. 2010. Terminological dictionary-reference book on construction and architecture. Lviv: Aral, p. 168.

[2] Verkhovna Rada of Ukraine, 2020. Law of Ukraine from 01.01.2020 375-VI: On Rest and Recreation of Children [online]. S.1., A.1. Available at: <https://zakon.rada.gov.ua/laws/show/375-17\#Text> [Accessed 19 May 2021].

[3] World of geography and tourism, 2020. Complexes of resort. [online] Available at: <http://ukr-tur.narod.ru/dovidnyk/slovnykk/k1/komlexvidp. htm $>$ [Accessed 10 Mart 2021].

[4] Verkhovna Rada of Ukraine, 2020. Law of Ukraine from 16.10.2020 № 324/95-BP: On Tourism [online]. S.1., A.1. Available at: <https://zakon.rada. gov.ua/laws/main/324/95-вp?lang=en\#Text $>$ [Accessed 19 May 2021].

[5] Ministry of Social Policy of Ukraine, 2020. Spa treatment. [online] Available at: <https://www.msp.gov.ua/timeline/Sanatornokurortnoelikuvannya.html > [Accessed 10 Mart 2021].

[6] Rutynskyy, M., 2007. Classification and Typology of resorts. Bulletin of Lviv University: geographical series, 34, p. 236-246.

[7 ArchDaily, 2020. Observation Tower. [online] Available at: <https:// www.archdaily.com/775818/observation-tower-arvydas-gudelis?ad source $=$ search fad medium $=$ search result all $>$ [Date of reference $2 \overline{9}$ February 2021].
[8] ArchDaily, 2020. Beijing Jinhai Lake International Resort. [online] Available at: https://www.archdaily.com/883534/beijing-jinhailake-international-resort-syn-architects?ad_source=search\&ad medium = search result all [Date of reference 29 February 2021]. [9] ArchDaily, 2020. Puritama Hot Springs. [online] Available at: https://www.archdaily.com/5955/puritama-hot-springs-german-delsol?ad_source =search\&ad_medium $=$ search_result_projects [Date of reference 29 February 20021].

[10] Karpaty-Slavsko, 2020. Polytechnic Recreation Base 2. [online] Available at: http://www.karpaty-slav.com/politeh.html [Date of reference 7 March 2021].

[11] NUBIP, 2020. Status and prospects of development of the main activities of the Faculty of Education, Recreation center Academic, Chernomorsk. [online] Available at: https://nubip.edu.ua/sites/ default/files/u130/tabir_chornomorsk_2018.pdf [Accessed 7 March 2021].

[12] Procherk.info, 2021. The resort town of Bukovel is one of the most successful projects in the history of modern Ukraine [online] Available at: https://procherk.info/resonance/2-cherkassynews/61219-misto-kurort-bukovel-odnin-iz-najuspishnishih-proektiv-u-istoriyi-suchasnoyi-ukrayini [Accessed 7 March 2021]. 